\title{
ESTUDO DOS ESPAÇOS LIVRES DO BAIRRO SANTA CECÍLIA, EM PIRACICABA, SP.
}

Henrique Sundfeld Barbin ${ }^{1}$, Giuliana Del Nero Velasco², Ivan André Alvarez ${ }^{3}$, Ana Maria Liner Pereira Lima ${ }^{4}$

(recebido em 17.10.2007 e aceito para publicação em 25.09.2008)

\section{RESUMO}

A necessidade de se obter parâmetros ambientais para subsídio do planejamento urbano vem crescendo. Um deles é o cálculo de índices que possam demonstrar como um determinado local se apresenta em relação às questões ambientais e sociais. São propostos três índices: Índice de Espaços Livres de Uso Público (IELUP), Índice de Cobertura Vegetal em Área Urbana (ICVAU) e Índice de Verde por Habitante (IVH). O Bairro Santa Cecília, no Município de Piracicaba, São Paulo, foi selecionado, por apresentar uma diversidade de características urbanísticas. Utilizando-se de fotografias aéreas, planta baixa do bairro e o software AutoCad 2000, realizou-se o cálculo dos três índices. O IELUP encontrado foi de 4,71 $\mathrm{m}^{2} / \mathrm{hab}$, número considerado baixo quando comparado a outras áreas já mensuradas, e ainda, nota-se a existência de vários vazios urbanos que, quando ocupados, aumentará a população, diminuindo ainda mais este valor. Para o ICVAU, que foi elevado (65,75\%), o quadro já é diferente, pois, existem na área muitas chácaras e um alojamento com grande área vegetada que, mesmo com a ocupação dos citados vazios, não abaixará na mesma proporção. Com relação ao IVH, de $263,90 \mathrm{~m}^{2} / \mathrm{hab}$, os comentários seguem o ICVAU, pois está diretamente relacionado à população.

Palavras-chave: espaço livre, arborização urbana, área verde, sistema de lazer, índice

\footnotetext{
1. engenheiro agrônomo, doutor em Agronomia - hsbarbin@uol.com.br

2. engenheira agrônoma, doutora em Agronomia, gdnvelas@esalq.usp.br

3 . engenheiro agrônomo, doutor em Agronomia - iaalvare@terra.com.br

${ }^{4}$. engenheira agrônoma, profa. Dra. do departamento de produção vegetal - ESALQ-USP amlplima@esalq.usp.br
} 


\title{
Study of open spaces in Santa Cecilia district, in the city of Piracicaba, SP
}

\begin{abstract}
The need to obtain environmental parameters allowance for urban planning is growing. One is the calculation of indexes that can show how a particular location is presented in relation to environmental and social issues. Three indexes were proposed: Index of free space for public use (IELUP), index of vegetation cover in Urban Area (ICVAU) and Green Index per inhabitant (IVH). The Santa Cecilia district, in the city of Piracicaba, São Paulo, was choosed because of it's urban characteristics. Using aerial photographs, maps of the district and the software AutoCad 2000, the three indexes were calculated. The IELUP found was 4,71 $\mathrm{m}^{2}$ /inhab., low when compared to other areas already measured, and, there are still empty places that, when filled, will increase the population, further reducing this figure. For the ICVAU, which was high $(65,75 \%)$, the picture is different because there are many little farms and a large area with vegetation that even with the occupation of empty places, won't diminish in the same proportion. The IVH, with $263,90 \mathrm{~m}^{2}$ /inhab., the comments are the same for the ICVAU, because it is directly related to population.
\end{abstract}

Key words: open spaces, arboriculture, green area, leisure, index

\section{INTRODUÇÃO}

Espaço livre é um termo abrangente, que inclui área verde, parque urbano, praça, sistema de lazer, jardim, área de preservação permanente e áreas particulares existentes dentro dos limites urbanos (LIMA et al., 1994). A sua presença na cidade é de vital importância para o bem estar da população, exercendo função ecológica, psicológica e estética.

A ocupação do solo há muito tempo tem sido feita de maneira desordenada, como ressalta Carrara (1992), relatando que existe a necessidade de se revisar os padrões de ocupação do solo urbano, levando-se em consideração o desequilíbrio entre os elementos formadores do sistema urbano que podem comprometer a qualidade de vida de seus habitantes. A vegetação representa papel fundamental neste sistema, desempenhando funções associadas a aspectos sociais, estéticos psicológicos e ecológicos, diminuindo, desta forma, os efeitos negativos do processo de urbanização (FORESTI; PEREIRA, 1987). 
O levantamento de áreas verdes subsidia a realização de um planejamento adequado da ocupação do solo, em espaços urbanos. O estabelecimento de medidas decisivas na preservação de áreas verdes urbanas é facilitado à medida que se tem à disposição dados, determinando a sua exata localização e a sua real superfície, permitindo futuros estudos ecológicos urbanos (LOMBARDO, 1985).

A criação de leis adequadas para desmembramentos de solo e sua respectiva fiscalização se tornam de extrema valia quando se fala em preservação do meio ambiente.

A Lei 6766/79, que dispõe sobre o parcelamento de solo urbano, tornou-se um importantíssimo instrumento jurídico e de planejamento para o desenvolvimento das cidades. Além de definir claramente em quais situações de risco ambiental não é permitido o parcelamento do solo, traz a obrigatoriedade de, no mínimo, 35\% da área loteada, ser destinada à implantação de áreas públicas, tais como, sistema de circulação, implantação de equipamentos urbano e comunitário (escolas, creches, centros de saúde, sede de bairros, entre outros), bem como, os espaços livres de uso público (sistemas de lazer). Houve, portanto, uma revolução no que se refere ao planejamento de centros urbanos, gerando uma situação de sistemas de lazer incrustados em meio a lotes.

Contudo, mesmo após a criação desta Lei (6766/79), muitas áreas destinadas ao lazer, tiveram sua finalidade mudada, sendo doadas à igrejas, clubes, associações, entre outras ditas "obras comunitárias". Até 1989, um grande número de doações foram feitas, causando um déficit de sistemas de lazer, que só foi sanado através do Artigo 180 da Constituição do Estado de São Paulo: "as áreas definidas em projeto de loteamento como áreas verdes ou institucionais não poderão, em qualquer hipótese, ter sua destinação, fim e objetivos, originalmente estabelecidos, alterados".

Um outro problema ainda não resolvido refere-se à escolha da parcela a ser destinada para a finalidade de lazer, dentro da área a ser loteada. Normalmente, o que ocorre é que as áreas eleitas são as piores do terreno, de solo raso (que dificultam a construção), íngremes e ainda, como a Lei não determina se os $10 \%$ do loteamento destinados ao sistema de lazer pode ser dividido ou não, os loteadores deixam sempre áreas onde o espaço não era suficiente para a locação de lote, para tal sistema de lazer.

No Município de Piracicaba, a Lei 2643 de 1985 (Lei que disciplina o parcelamento do solo), através do Artigo $18^{\circ}$, Parágrafo $4^{\circ}$, determina que um técnico da Prefeitura Municipal de Piracicaba é quem designará, na área a ser loteada, a destinada ao lazer.

Quando se fala em área de preservação permanente, definido pela Lei Federal 4.771, de 1965 (Código Florestal), a situação se agrava mais ainda. Pode-se observar nas cidades corpos d'água totalmente impermeabilizados e ainda canalizados, nascentes 
aterradas, desrespeitando totalmente os preceitos ecológicos. No Santa Cecília, os cursos d’água foram respeitados e reflorestados em parte, embora a nascente não esteja protegida. Já o Ribeirão Piracicamirim foi retificado e uma de suas margens foi reflorestada, enquanto que a outra não, com o intuito de se viabilizar as obras rotineiras de desassoreamento.

A adequação da quantidade de espaços livres para a população que dela usufrui é traduzida através de índices de área verde; porém, não há consenso na utilização desses diversos índices (CAVALHEIRO; NUCCI, 1998).

Guzzo (1999) utilizou três desses parâmetros para relacionar a presença de áreas verdes: Índice de Espaços Livres de Uso Público (IELUP), medido em $\mathrm{m}^{2} / \mathrm{hab}$, que é a quantidade de área de espaços livres urbanos de uso público, ou seja, as áreas cujo acesso das pessoas é livre. São somados nesse calculo as áreas de: praças, parques, sistemas de lazer e cemitérios; Índice de Cobertura Vegetal em Área Urbana (ICVAU), medida em porcentagem, é a proporção de área coberta com vegetação em função da área total estudada. Abrange as áreas públicas e particulares; e Índice de Verde por Habitante (IVH), medido em $\mathrm{m}^{2} /$ hab, é a quantidade de cobertura vegetal dividido pelo número de habitantes do local. Os índices citados servem como padrão de referência de qualidade de vida para uma população que habita um determinado local. Alguns pesquisadores já adotaram estes índices e realizaram cálculos para suas áreas de estudo, como é o caso de setores do Município de Ribeirão Preto (GUZZO, 1999) e o Distrito de Santa Cecília, em São Paulo (NUCCl, 1996).

O Bairro Santa Cecília é relativamente novo, de 121,66 hectares, e teve suas terras desmembradas em etapas sendo a primeira no final da década de 60 , início da década de 70, com a implantação do Loteamento Jardim Brasília; a segunda, no final da década de 70, início da de 80, com a implantação do Parque Santa Cecília (aprovado em 1975), do Jardim Água Seca (1979) e do Recanto Tropical (1980); e a terceira, a partir de 1985, com a locação do Loteamento Santa Cecília, implementado em 1987.

Existem ainda, áreas particulares que não pertencem a nenhum loteamento, constituindo-se por invasões, ocupações em remanescentes vegetais, chácaras já existentes no local e divisão em glebas não oficializada (Chácara Naval), ou seja, um desmembramento entre as partes, porém sem registro em cartório.

Tendo em vista que a legislação urbanística é periodicamente alterada e, devido ao fato de o desmembramento ter sido realizado ao longo de vários anos, uma diversidade de características urbanísticas pode ser encontrada na área; desde o nível sócio-econômico até a presença dos elementos vegetais, exigindo uma análise detalhada de suas características. Esta heterogeneidade urbanística foi determinante na escolha da área a ser estudada.

\section{MATERIAL E MÉTODOS}


O Bairro Santa Cecília (Figura 1), situa-se na zona Leste do Município de Piracicaba, Estado de São Paulo, Brasil, e dista aproximadamente $3,5 \mathrm{~km}$ de sua área central. É cercado pelo Campus da USP ao norte; Bairro Vila Independência ao oeste, Bairro Morumbi ao sul e Bairro Abaeté ao leste.

O Bairro é formado por cinco loteamentos de diferentes padrões urbanísticos e áreas particulares.

Há uma nascente e um córrego afluente do Ribeirão Piracicamirim, onde foram traçadas suas Áreas de Preservação Permanente (APP), seguindo a Lei Federal 4.771/65, e portanto tendo sido considerado: 50 metros de raio para a nascente e 30 metros de cada lado da margem para o córrego. A APP do Ribeirão Piracicamirim, também de 30 metro, foi traçada.

Foram utilizados para realização do trabalho:

a) Planta baixa digital do município atualizada e elaborada a partir de levantamento aerofotogramétrico realizado em 1995 contendo a área total dos loteamentos, bem como os elementos que os constituem segundo a Lei 9799/79 (Sistema Viário, Quadras, APPs, Sistema de Lazer, Área Institucional, dentre outros);

b) Fotografias aéreas verticais - 1945 (1:10.000), 1962 (1:25.000), 1969 (1:8.000), 1973 (1:8.000); 1978 (1:5.000), 1995 (1:25.000) e 2000 (1:25.000);

c) Software Auto-Cad 2000;

d) Lei Municipal 2643/85, Lei Federal 4.771/65, Lei Federal 6.766 /79, Decreto Federal 99.274/90;

e) Registros das áreas em cartório;

f) Censo demográfico realizado pelo IBGE em 2.000;

g) Informações cadastrais existentes na Secretaria Municipal de Planejamento, fornecida pelos técnicos no setor.

As fotografias aéreas dos diferentes anos foram utilizadas para o acompanhamento visual da expansão urbana no bairro.

Através da ferramenta de medida do software Auto-Cad 2000, a planta baixa do bairro em formato digital e observações feitas em campo foram calculadas as áreas referentes: ao sistema de lazer, área de preservação permanente (APP), total de áreas cobertas com vegetação (natural ou implantada), área total do bairro e área total de cada loteamento, verde de acompanhamento viário, área "non aedificandi" e áreas particulares presentes no mapa. As áreas particulares representadas por terrenos baldios e quintais foram determinadas através da identificação visual da fotografia e utilização do Autocad, sendo consideradas as áreas maiores que $10 \mathrm{~m}^{2}$. 


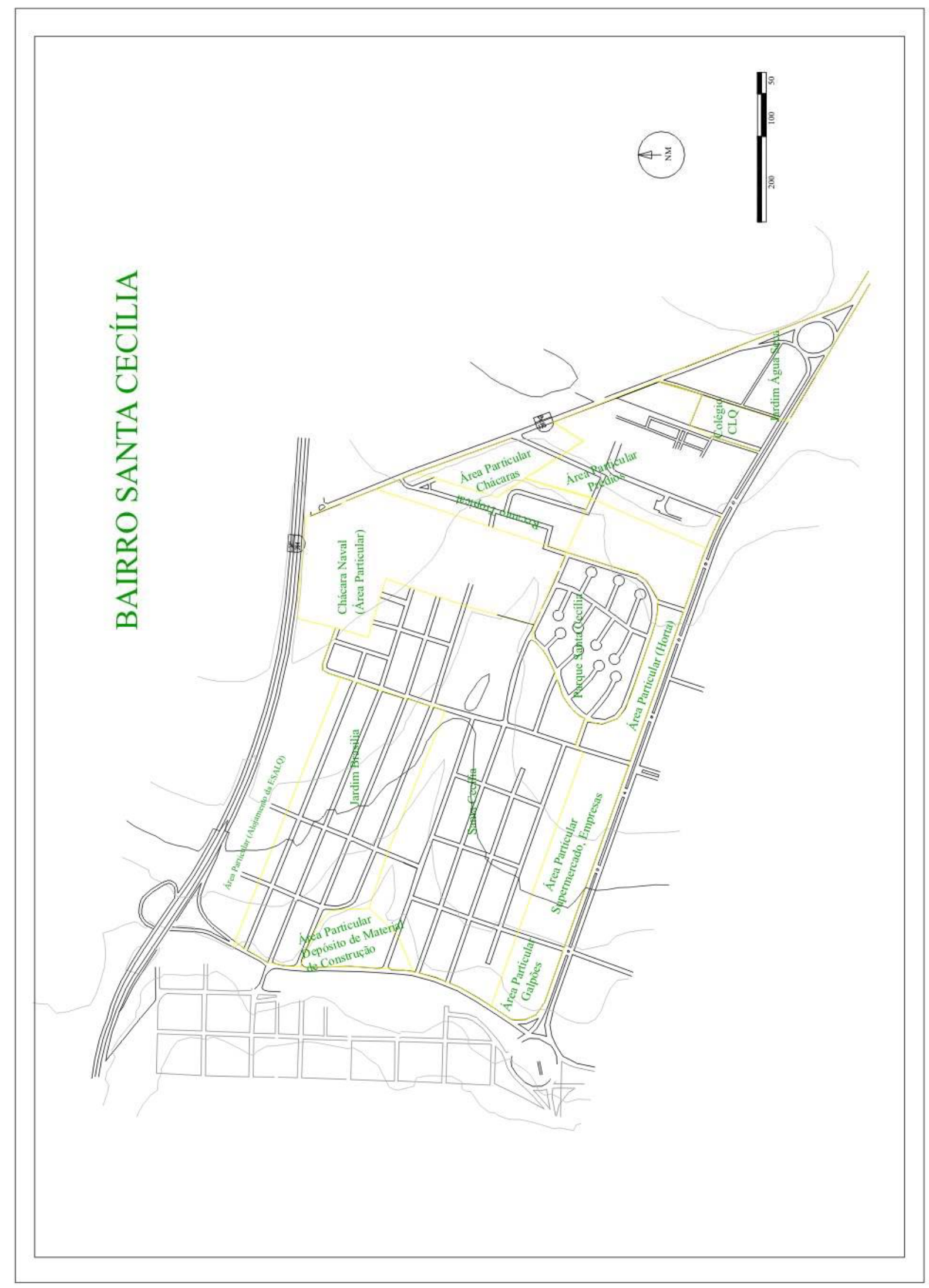

Figura 1 - Os loteamentos e áreas particulares que compõem o Bairro. 
Estudou-se também, se foram implantados os sistemas de lazer exigidos por lei, de que forma foram dispostos e se estão devidamente implantados.

Os Índices foram calculados seguindo as seguintes fórmulas:

- Índice de Espaços Livres de Uso Público

IELUP $=\frac{\text { Áreas Verdes Públicas }}{\text { Habitantes }}\left(\mathrm{m}^{2} / \mathrm{hab}\right)$

Onde:

Áreas Verdes Públicas - quantidade de área de espaços livres urbanos de uso público (as áreas cujo acesso das pessoas é livre). São somados nesse calculo as áreas de: praças, parques, sistemas de lazer e cemitérios;

Habitante - número total de habitantes da área estudada;

- Índice de Cobertura Vegetal em Área Urbana

ICVAU $=\frac{\text { Área Coberta por Vegetação }}{\text { Área Total }} \times 100 \quad(\%)$

Onde:

Área Coberta por Vegetação - toda área coberta por vegetação sendo esta arbórea, arbustiva e/ou gramíneas;

Área Total - área total estudada.

- Índice de Verde por Habitante

$\mathrm{IVH}=\quad \frac{\text { Área Coberta por Vegetação }}{\text { Habitantes }}\left(\mathrm{m}^{2} / \mathrm{hab}\right)$

Onde:

Área Coberta por Vegetação - toda área coberta por vegetação sendo esta arbórea, arbustiva e/ou gramíneas;

Habitante - número total de habitantes da área estudada;

\section{RESULTADOS E DISCUSSÃO}

\subsection{ESTUDO DAS FOTOGRAFIAS AÉREAS}

O estudo das fotografias aéreas de diversos anos mostrou a evolução do desmembramento de terras na área.

Na Figura 2, contemplando apenas parte da área, a fotografia aérea do ano de 1945 , retrata que havia na área de estudo, alguns pomares, plantações anuais e o Ribeirão Piracicamirim ainda com seus meandros. Nenhum indício de urbanização fora detectado. 


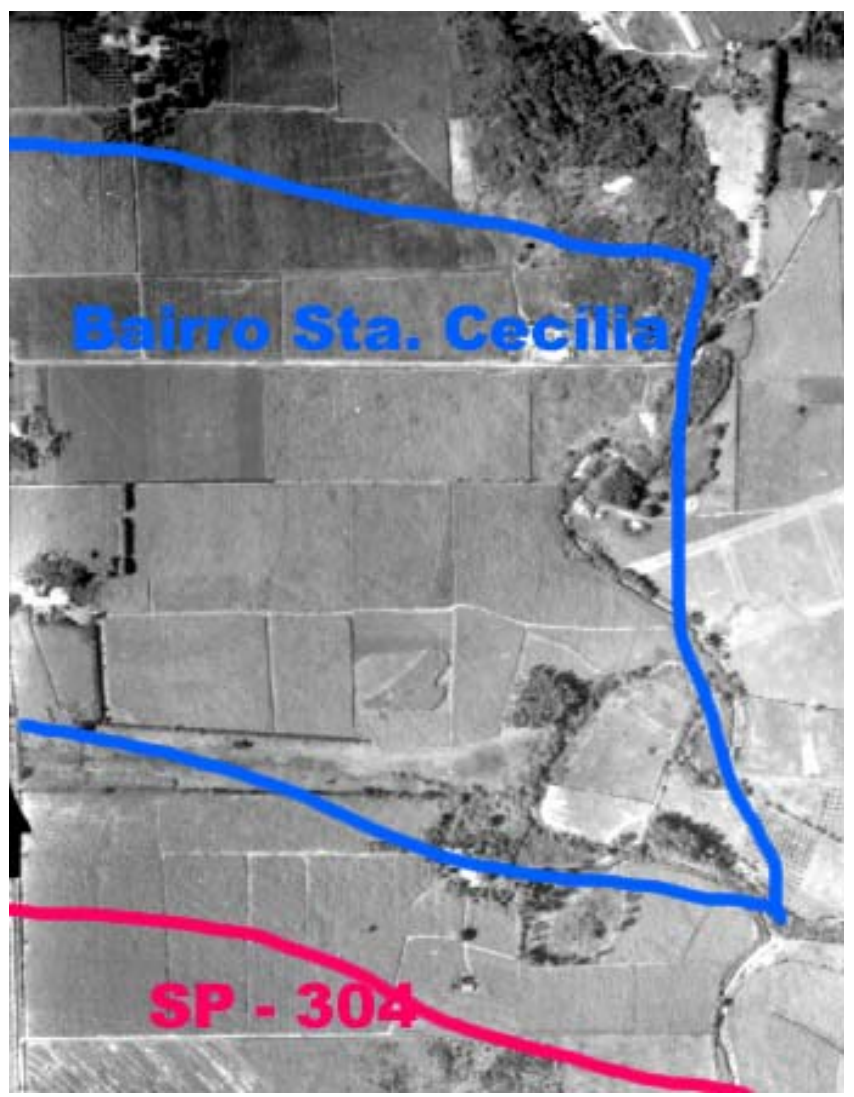

Figura 2. - Fotografia aérea de 1945 mostrando parte da área em estudo.

No ano de 1962, desta vez contemplando a área toda (conforme demarcação na foto) o quadro se manteve o mesmo (Figura 3). Nota-se que há urbanização em terreno lindeiro ao estudado, mas, talvez devido à dificuldade de transposição do curso d'água, a área de estudo encontra-se com características rurais.

Quanto aos índices estudados, até esta data, nenhum índice pode ser calculado, uma vez que não há habitantes na região de estudo. Sendo assim, não se justifica o cálculo do ICVAU, que independe de habitantes - e sim da proporção de área vegetada pela área total estudada - pois, os índices foram criados para determinar a quantidade de espaços livres para a população. 


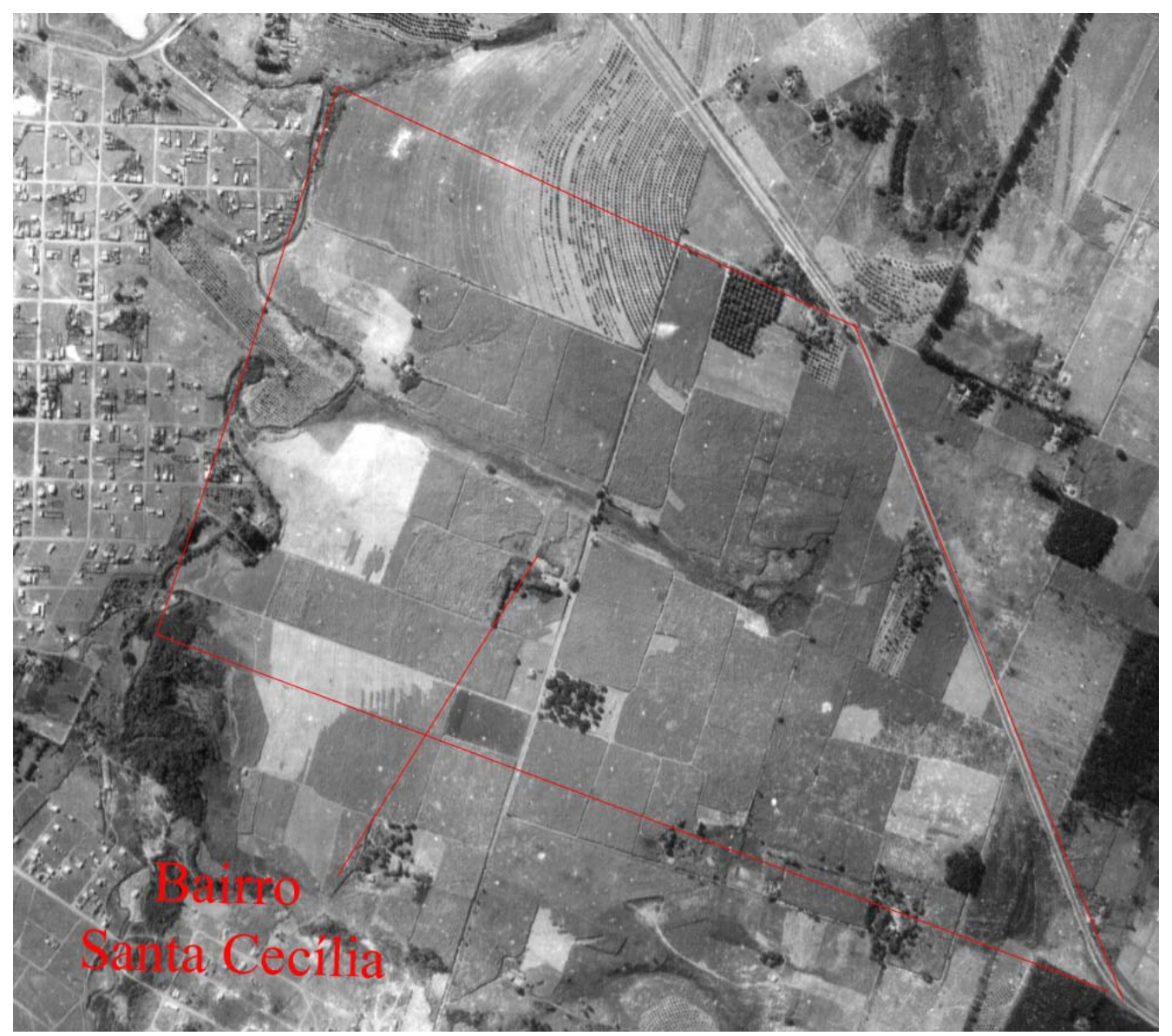

Figura 3 - Fotografia aérea de 1962 mostrando a área ainda não urbanizada.

A Figura 4 mostra que, em 1969, algumas construções residenciais do Loteamento Jardim Brasília, podiam ser observadas, entrecortadas por arruamentos.

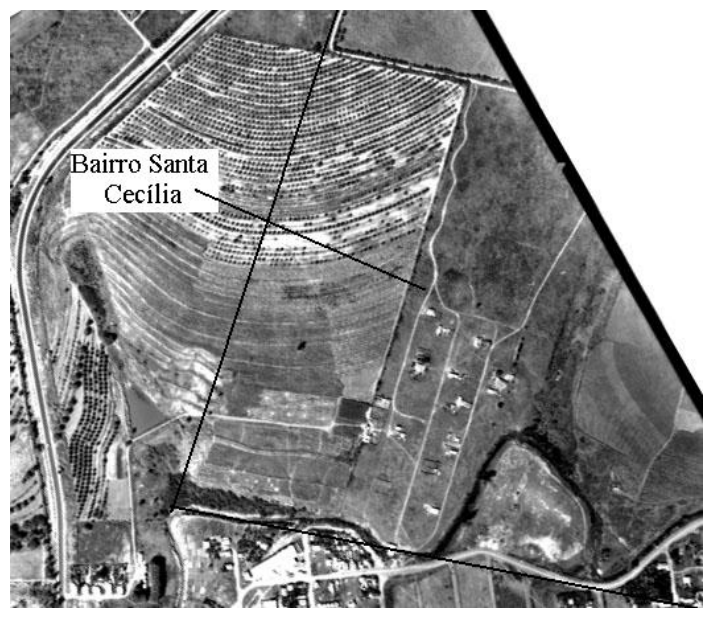

Figura 4 - Fotografia aérea de 1969, mostrando as primeiras intervenções urbanísticas na área.

Em 1973, o Ribeirão Piracicamirim aparece em processo de retificação e a ocupação continua praticamente a mesma, como pode ser visto na Figura 5. Em 1978 (Figura 6), a ocupação já é bem maior (somente no loteamento Jardim Brasília) e notam-se as primeiras intervenções dos outros loteamentos que foram sendo criados nessa época; o Ribeirão Piracicamirim já se apresentava retificado. 

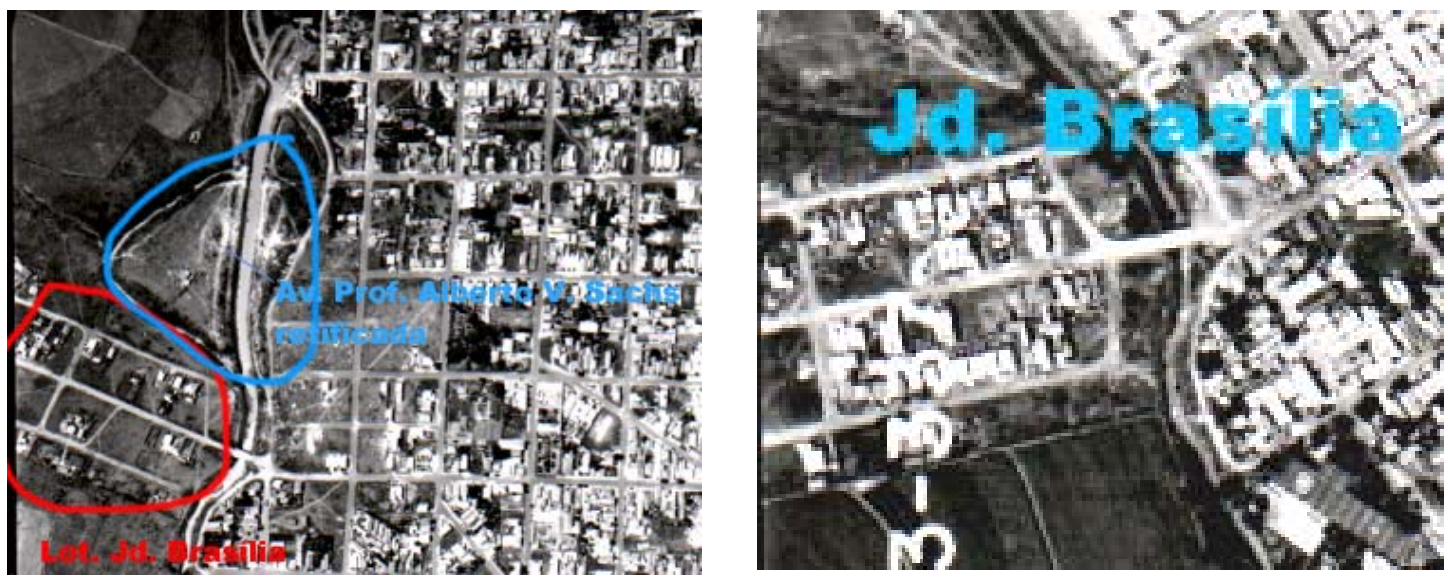

Figura 5 - Fotografia de 73, retificação do Figura 6 - Em 1978, um maior adensamento. Ribeirão e presença da Avenida.

Neste período já é possível realizar os cálculos dos três índices, mas, tendo em vista que os lotes se encontram desprovidos de vegetação, os mesmos seriam elevados, retratando uma situação típica de momento. A previsão é de que todos diminuíssem a medida que as construções fossem sendo erguidas e a população ocupando os espaços.

Entre 1978 e 1993, não há fotos aéreas que registrem a situação do bairro, mas sabe-se que gradualmente os outros loteamentos foram sendo ocupados. Em 1995 todos os loteamentos já estavam implantados e acelerava-se a ocupação com construções, como observado na Figura 7. Empresas já haviam se instaladas na porção esquerda da fotografia e na porção leste outras fábricas e conjuntos residenciais já se faziam presentes.

De 1995 a 2000, houve o acréscimo de prédios unifamiliares e um pequeno aumento na urbanização como pode ser visto na Figura 8. De qualquer forma, devido à pequena distância da região central da cidade, ao aquecimento imobiliário presente no Município, ainda podem ser encontrados diversos terrenos desprovidos de construções, situação não comum quando comparado a outros bairros da cidade e a outros municípios. 


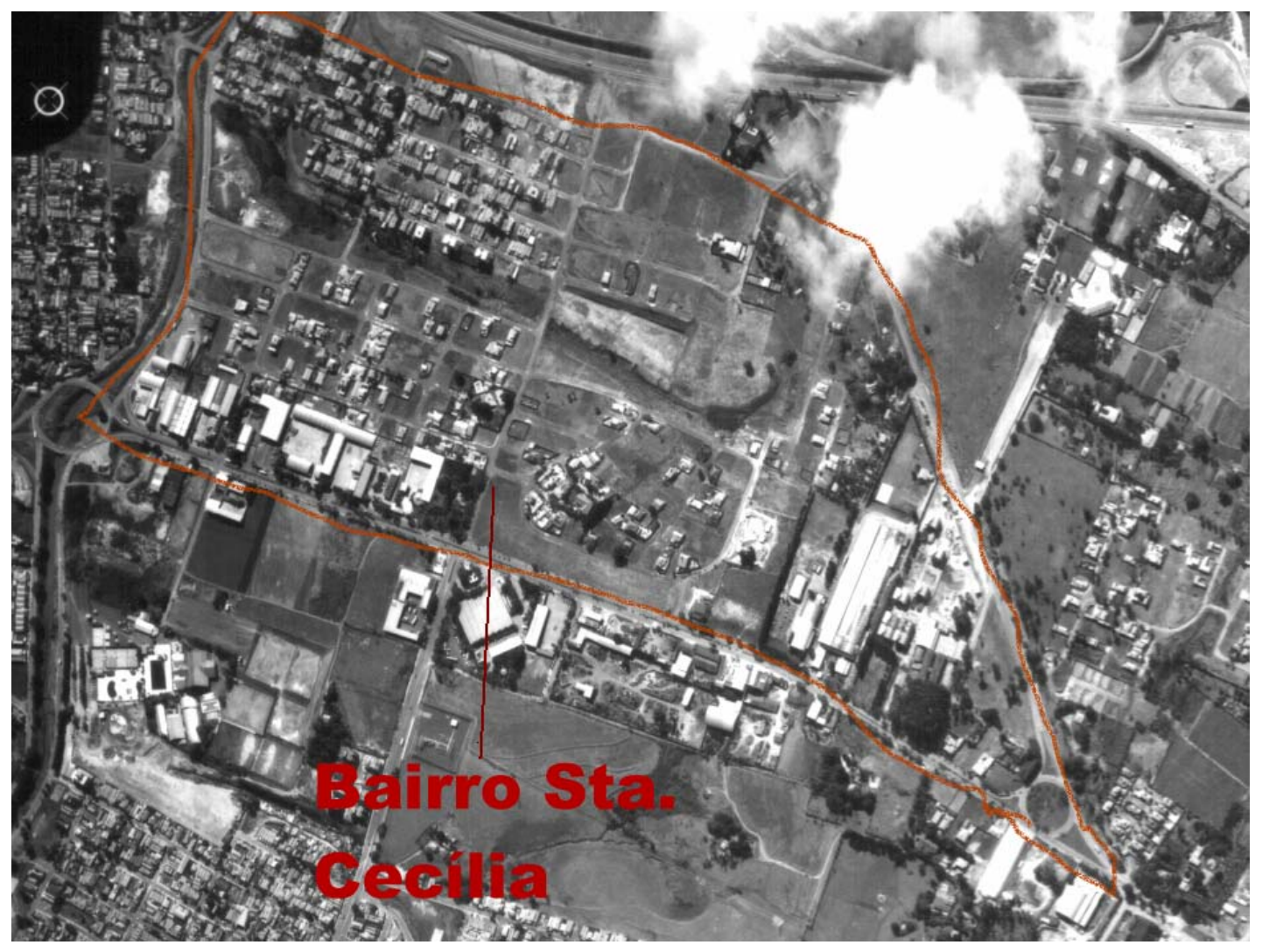

Figura 7 - Fotografia aérea de 1995, todos os loteamentos implantados.

\subsection{CÁLCULO DOS ÍNDICES}

Após a total implantação dos loteamentos no Bairro Santa Cecília, observa-se que o bairro é composto por glebas de características bastante heterogêneas.

No Jardim Brasília, predominam lotes pequenos $(5 \times 25 \mathrm{~m})$, que aumentam o adensamento de residências, causando maior impermeabilização do solo e conseqüentemente menor cobertura vegetal. Também contribui para um maior número de habitantes por hectare, uma vez que em uma mesma área, uma grande quantidade de unidades residenciais é construída em relação a um loteamento de lotes maiores e de maior poder aquisitivo. O sistema de lazer foi desmembrado em pequenas partes, sendo que na maior delas foi locada uma creche. As outras áreas encontram-se não implantadas.

No Parque Santa Cecília, as características são bem diferentes do anterior: os lotes são maiores (10 X 30 m), as ruas são terminadas em "cul de sac", onde se prolongam áreas ajardinadas que compõem os Sistemas de Lazer. Estes estão implantados, cobertos por gramados e arborizados.

O Jardim Água Seca, de 1979, possui apenas uma parte inserida nesse bairro, porém de características similares ao anterior. O Sistema de Lazer foi locado em frente ao Colégio CLQ, na porção leste da área de estudo e não se encontra implantado. É um potencial, uma vez que pode se tornar uma área para o uso público. 
O Loteamento Santa Cecília, o mais recente, implementado em 1987, com terrenos de $12 \times 20$ m sendo também de padrão elevado. Porém os Sistema de Lazer foram locados sobre no prolongamento das APPs, na época, prática permitida pela legislação vigente. À época, as faixa de APP era de $5 \mathrm{~m}$ em cursos d'água com até 10 metro de largura. Os Sistemas de Lazer foram locados no prolongamento das APPs na tentativa de melhorar a proteção do córrego. Na prática, como em 1989 a faixa de APP passou de $5 \mathrm{~m}$ para $30 \mathrm{~m}$, parte deste sistema de lazer foi tragado pela faixa de preservação permanente. As áreas não englobadas foram arborizadas, impossibilitando a implantação de equipamentos de lazer ativo.

O Recanto Tropical, aprovado em 1980, apresenta lotes de 12 X 30 m e é onde está inserida a nascente do córrego que deságua no Ribeirão Piracicamirim. Parte do sistema de Lazer também está locado sobre as APPs o que causa mais uma vez um déficit de áreas para o lazer da população. Outra parte está em terreno lindeiro, também na cabeceira da nascente.

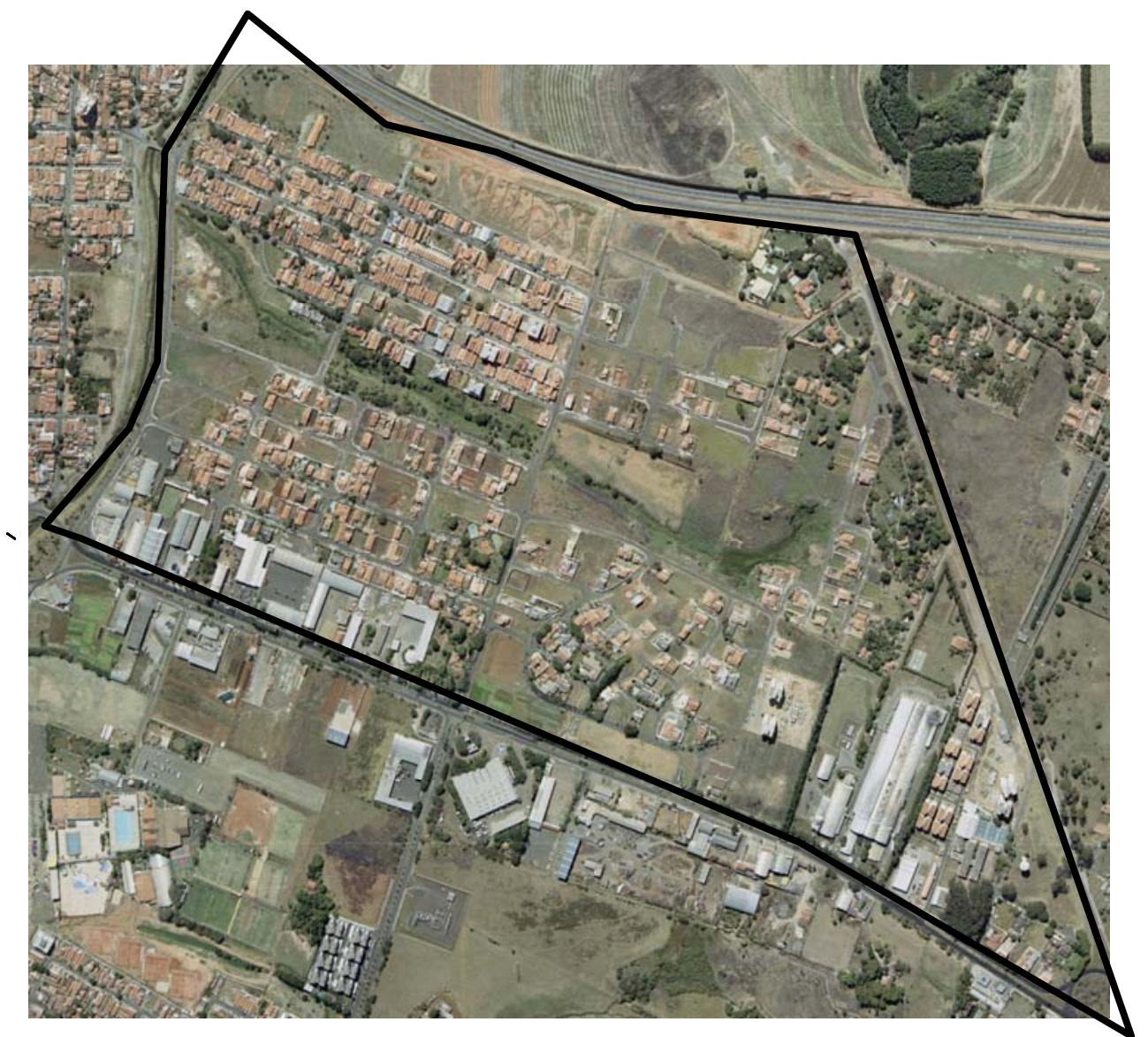

Figura 8. Fotografia aérea de 2000, com o acréscimo de residências em relação aos anos anteriores.

Existem ainda, áreas particulares que não pertencem a nenhum loteamento, constituindo-se por invasões, ocupações em remanescentes vegetais, chácaras já 
existentes no local e divisão em glebas não oficializada (Chácara Naval), ou seja, um desmembramento entre as partes, porém sem registro em cartório.

As áreas que margeiam as rodovias que delimitam o Bairro possuem as áreas "nom aedificandi" que, apesar de ser faixa para infiltração de águas, não proporciona o lazer à população. Há também os "verdes de acompanhamento viário" que são os canteiros centrais de avenida e as rotatórias. Diversas áreas de APP foram ocupadas indevidamente ficando impossibilitadas de exercer sua função. Os espaços livres levantados neste trabalho são descritos por loteamentos (Tabela 1) e demonstrados na Figura 8.

TABELA 1*. Medidas dos loteamentos existentes no bairro.

\begin{tabular}{|c|c|}
\hline Loteamentos & Medida $\left(\mathrm{m}^{2}\right)$ \\
\hline \multicolumn{2}{|l|}{ JARDIM BRASÍLIA } \\
\hline Sistema de lazer não implantado & $1.378,00$ \\
\hline APP & $15.390,75$ \\
\hline APP ocupada & $4.402,02$ \\
\hline Área total & $149.010,00$ \\
\hline \multicolumn{2}{|l|}{ PARQUE SANTA CECÍLIA } \\
\hline Sistema de lazer implantado & $2.597,50$ \\
\hline Área total & $111.102,72$ \\
\hline \multicolumn{2}{|l|}{ LOTEAMENTO SANTA CECÍLIA } \\
\hline Sistema de lazer implantado & $9.605,00$ \\
\hline Sistema de lazer ocupado & $1.035,00$ \\
\hline APP & $40.168,11$ \\
\hline APP ocupada & $8.184,45$ \\
\hline Área total & $320.524,00$ \\
\hline \multicolumn{2}{|l|}{ RECANTO TROPICAL } \\
\hline Sistema de lazer implantado & $2.059,00$ \\
\hline APP & $2.390,00$ \\
\hline Área total & $38.282,00$ \\
\hline \multicolumn{2}{|l|}{ JARDIM ÁGUA SECA } \\
\hline Sistema de lazer não implantado & $14.065,76$ \\
\hline Área total & $50.783,64$ \\
\hline \multicolumn{2}{|l|}{ DEMAIS ÁREAS (FORA DOS LOTEAMENTOS) } \\
\hline Verde de acompanhamento viário & $16.444,25$ \\
\hline Área Particular (APP ocupada) & 530,34 \\
\hline Área "non aedificandi" & $26.184,68$ \\
\hline
\end{tabular}




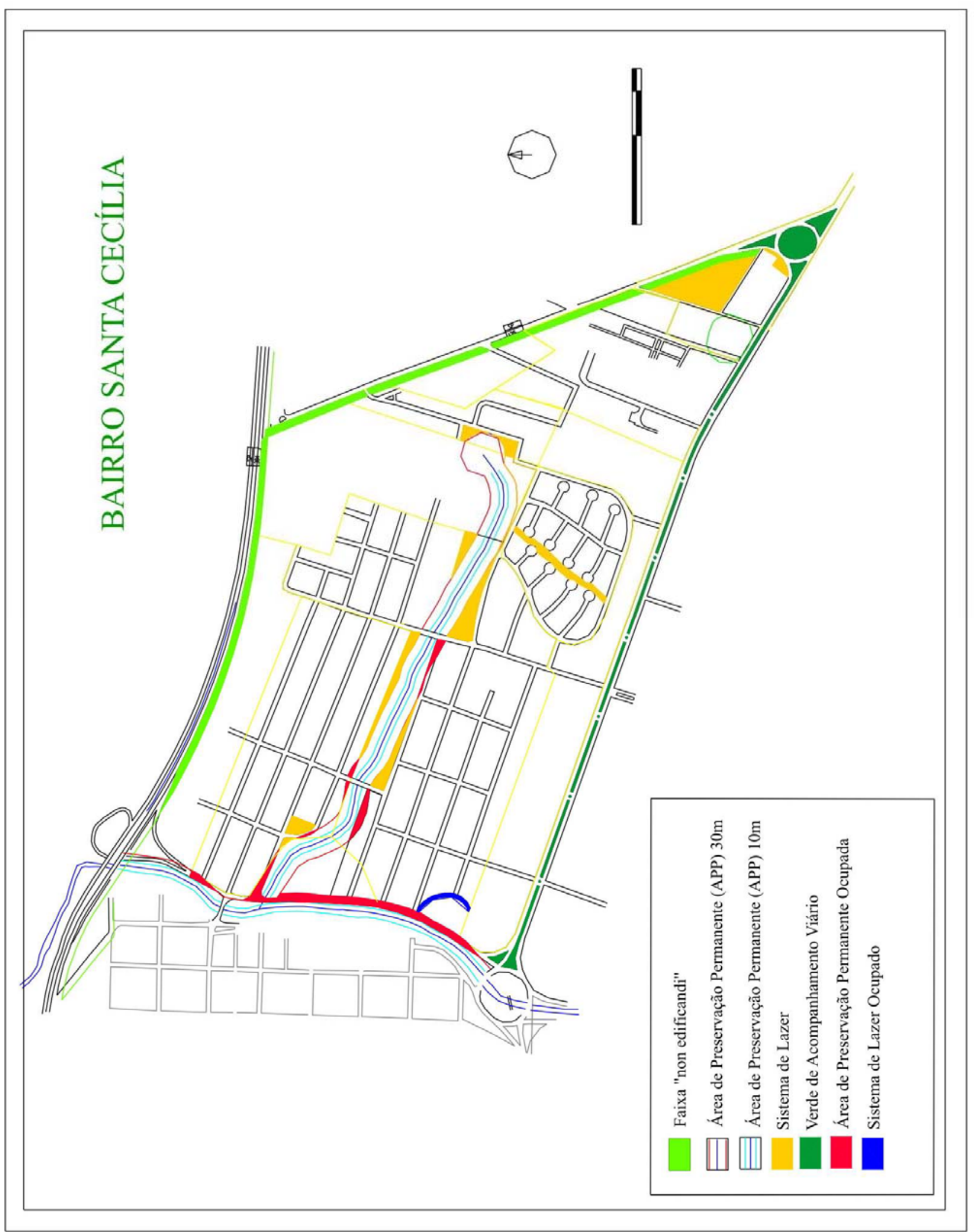

Figura 8 - Planta baixa com todas as áreas levantadas. 
Para o cálculo dos índices, utilizou-se a população levantada pelo IBGE no Censo de 2000 e obteve-se o dado de: $\mathbf{3 . 0 3 1}$ habitantes para o Bairro.

A Área Total do Bairro é de 1.216.600,00 $\mathrm{m}^{2}$

O somatório dos Espaços Livres Públicos disponíveis ao uso público, aqui representadas pelos Sistemas de Lazer dos loteamentos descontando os utilizados indevidamente (sistema de lazer do Santa Cecília com 1.035,00 $\mathrm{m}^{2}$ ) e os ainda não implantados, perfaz: 14.261,50 $\mathrm{m}^{2}$, conforme Tabela 2.

Tabela 2. Somatório das áreas verdes destinadas ao uso público.

\begin{tabular}{|l|r|}
\hline \multicolumn{1}{|c|}{ Espaço Livre Público } & \multicolumn{1}{c|}{ Medida $\mathbf{( m}^{\mathbf{2}} \mathbf{)}$} \\
\hline Sistema de lazer do Parque Santa Cecília & $2.597,50$ \\
\hline Sistema de lazer do Santa Cecília & $9.605,00$ \\
\hline Sistema de lazer do Recanto Tropical & $2.059,00$ \\
\hline Total de Espaços Livres Públicos Implantados & $\mathbf{1 4 . 2 6 1 , 5 0}$ \\
\hline
\end{tabular}

Quanto à Área Total Vegetada, foram somadas todas as áreas vegetadas presentes no Bairro, independente de uso público ou particular.

As áreas caracterizadas neste item estão representadas na Tabela 3.

Tabela 3. Áreas de Cobertura Vegetal do Bairro Santa Cecília.

\begin{tabular}{|l|r|}
\hline \multicolumn{1}{|c|}{ Loteamentos } & \multicolumn{1}{c|}{ Medida $\mathbf{( m}^{\mathbf{2}} \mathbf{)}$} \\
\hline Sistema de lazer Jardim Brasília & $1.378,00$ \\
\hline APP Jardim Brasília & $15.390,75$ \\
\hline Sistema de lazer Parque Santa Cecília & $2.597,50$ \\
\hline Sistema de lazer Santa Cecília & $9.605,00$ \\
\hline APP Santa Cecília & $40.168,11$ \\
\hline Sistema de lazer Recanto Tropical & $2.059,00$ \\
\hline APP Recanto Tropical & $2.390,00$ \\
\hline Sistema de lazer Jardim Água Seca & $14.065,76$ \\
\hline Verde de acompanhamento viário & $16.444,25$ \\
\hline Área Particular (APP ocupada) & 530,34 \\
\hline Área "non aedificandi" & $26.184,68$ \\
\hline Áreas Particulares (Terrenos e quintais) & $669.079,74$ \\
\hline Total Cobertura Vegetal & $\mathbf{7 9 9 . 8 9 3 , 1 3}$ \\
\hline
\end{tabular}

Os resultados dos cálculos dos três índices que refletem a presença do verde no bairro, segundo Guzzo (1999), são apresentados a seguir:

1. Índice de Espaços Livres de Uso Público (IELUP) $=\frac{14.261,50}{3.031}=\mathbf{4 , 7 1} \mathbf{~ m}^{2} /$ habitante

2. Índice de Cobertura Vegetal em Área Urbana $\left(\right.$ ICVAU) $=\frac{799.893,13}{1.216 .600,00}=65,75 \%$ $\frac{799.893,13}{1.216 .600,00}$

3. Índice de Verde por Habitante $(\mathrm{IVH})=\underline{799.893,13}=\mathbf{2 6 3 , 9 0} \mathrm{m}^{\mathbf{2}} /$ habitante 3.031 
Cabe lembrar que para a realização dos cálculos, utilizou-se a legislação atualizada, ou seja, em locais onde o sistema de lazer teve sua finalidade modificada, a área referente não entrou no cálculo do IELUP.

Pode-se observar na Tabela 4, a comparação com os dados obtidos para o Município de Ribeirão Preto e o Distrito de Santa Cecília, em São Paulo.

TABELA 4. Dados das áreas citadas

\begin{tabular}{|c|c|c|c|}
\hline Local & IELUP (m²/hab) & ICVAU (\%) & IVH ( $\left.\mathrm{m}^{2} / \mathrm{hab}\right)$ \\
\hline Bairro Santa Cecília (Piracicaba - SP) & 4,71 & 65,75 & 263,90 \\
\hline Região Central (Ribeirão Preto - SP) & 3,60 & 7,5 & 10,00 \\
\hline Subsetor N-5 (Ribeirão Preto - SP) & 9,58 & 6,7 & 12,96 \\
\hline Distrito Santa Cecília (São Paulo - SP) & 0,92 & 7,0 & 2,96 \\
\hline
\end{tabular}

Analisando-se a tabela acima, observa-se que o IELUP da área em estudo está próximo ao da Região Central de Ribeirão Preto. O Bairro é desprovido de áreas destinadas ao lazer e só apresenta este índice por possuir muitas áreas ainda não habitadas, principalmente os lotes em loteamentos que um dia contarão com moradores. E ainda, chama-se a atenção para o uso ao qual foi destinado o Sistema de Lazer implantado. Estas foram totalmente revegetadas com espécies de árvores nativas sendo uma extensão da restauração das APPs do córrego que corta o Bairro. A beleza cênica é inevitável, porém praticamente impossibilitou a prática do lazer ativo (esportes motores).

Esperava-se que este índice fosse semelhante ao Subsetor N-5 de Ribeirão Preto por se trata de áreas residenciais e não semelhante a região central. O Distrito de Santa Cecília em São Paulo, e o centro da cidade de Ribeirão Preto, são áreas mais antigas, de maior valor especulativo e conseqüentemente mais adensadas. Apesar dos loteamentos examinados terem seguido a legislação, a falta de espaços destinados ao lazer da população é uma constante nesse bairro, uma vez que tais áreas, previstas no loteamento, são, em quase a sua totalidade, lindeiros às Áreas de Preservação Permanente e, com as mudanças na legislação (Código Florestal em 1965) relacionadas à largura das faixas determinadas para proteção de mananciais, as áreas de lazer tiveram sua finalidade modificada, restringindo-as a estreitas faixas vizinhas às APPs. O que ficou de fora das novas APPs, foram implantadas, mas com plantios de árvores, o que praticamente impossibilita o lazer ativo.

Com relação ao ICVAU, nota-se que o da área em estudo é muito maior que os outros relacionados, porém, trata-se de um bairro ainda em implantação, com grande número de terrenos baldios além de algumas chácaras e áreas particulares, principalmente a faixa da ESALQ, que forma um grande maciço vegetal em uma das laterais do bairro. Há também a área "nom aedificandi" da Rodovia Luiz de Queiroz que, junto com a APP contribuiu bastante para o aumento do índice. 
Quanto ao IVH, maior discrepância quando se compara com as outras áreas, é também devido ao bairro estar em implantação, aos fatores já comentados e a população residente ainda pequena. Os valores dos índices citados tendem a diminuir bastante à medida que os lotes sejam ocupados.

Nota-se na Figura 8, que uma área, designada a sistema de lazer, foi ocupada ilegalmente e algumas áreas que deveriam ser de preservação permanente, estão cobertas com ruas e lotes.

Os parâmetros sobre índices, acima expostos, podem ser discutidos, mas como bem coloca Cavalheiro (1995) o índice não deve ser encarado como um valor absoluto e isolado em si, mas como um ponto de reflexão sobre o planejamento do sistema de espaços livres de determinada cidade e como parâmetro de comparação entre urbes, assinalando para a avaliação da qualidade ambiental e de vida que se apresentam. Assim, como ocorre em qualquer cidade, também em Piracicaba, existem relações com a paisagem muito peculiares. Em um plano de manejo, existem espaços onde a paisagem poderá ser mantida integralmente, assim como áreas que poderão sofrer intervenção, no sentido de propiciar melhor qualidade de vida, tais propostas podem ser baseadas em conceito de área verde ou de espaço livre que contenha área verde.

Deve-se atentar para o tipo de implantação que se tem em um sistema de lazer e para o tipo de lazer que se pretende em uma área. Caso a implantação seja apenas com a arborização, como é o caso do Bairro Santa Cecília é sabido que o lazer será apenas contemplativo, interpretativo (no caso de criação trilhas) e educacional. Se o objetivo é o lazer ativo, deve-se implantar outros equipamentos públicos a fim de proporcionar atividades motoras aos usuários das áreas verdes. O Bairro em estudo tem uma boa cobertura vegetal e uma beleza cênica devido aos plantios realizados.

Quanto ao lazer da população, o fato de terem inúmeros metros quadrados ainda não construídos e ainda uma extensa área institucional não implantado -que faz as vezes do sistema de lazer - parece não fazer muita falta quando se ouve a população. O problema é que no futuro, quando as áreas deverão estar urbanizadas, a falta do espaço para o lazer, com certeza será sentido.

Cabe lembrar que, por não haver uma metodologia única, baseada nos mesmos parâmetros, para o cálculo dos referidos índices, algumas cidades usam o índice de verde por habitante para exprimir a quantidade de sistema de lazer por munícipe, o que causa a grande discrepância entre índices de diferentes municípios.

\section{CONCLUSÕES}

O Bairro foi ocupado em etapas, porém, ainda não está totalmente implantado. A mudança de legislação ambiental dificultou a implantação total dos loteamentos, o que, de 
certa forma propiciou uma maior presença de verde do que nos Bairros adjacentes. Os cálculos dos índices de áreas verdes por habitante demonstraram que alguns estão acima do exigido por lei, porém, com a crescente ocupação da área, estes índices devem diminuir. Há a necessidade de mudanças nas leis municipais que regem o município, evitando as construções adensadas.

É de primordial importância que sejam aprofundadas as discussões referentes aos índices de verde por habitante.

\section{REFERÊNCIAS BIBLIOGRÁFICAS}

CAVALHEIRO, F.; NUCCI, J.C.; Espaços livres e qualidade de vida urbana. Paisagem, Ambiente, Ensaios. São Paulo, n. 11, p. 277-288. 1998.

CARRARA, A. L. R. Análise comparativa dos índices de vegetação em áreas urbanas obtidas de dados TM-LANDSAT e HRV-SPOT: Cidade de Taubaté. INPE. São José dos Campos, 1992. 193p.

FORESTI, C.; PEREIRA, M. D. B.; FLORENZANO, T. G. Aplicação dos índices de vegetação nos estudos do ambiente urbano de São José dos Campos com utilização de dados TM-LANDSAT. In Congresso Brasileiro de Defesa do Meio Ambiente, 1. Rio de Janeiro, 1987. Anais. Rio de Janeiro: 1987. p.293-306

GUZZO, P. Estudo dos Espaços livres de uso público da cidade de Ribeirão Preto/SP, com detalhamento da cobertura vegetal e áreas verdes públicas de dois setores urbanos. Rio Claro - SP., 1999. 125p. (Dissertação de mestrado. Instituto de Geociências e Ciências Exatas da UNESP/Campus Rio Claro)

LEI MUNICIPAL n² 2643/85. Disciplina o Parcelamento do solo.

LEI FEDERAL $n^{0} 6766 / 79$. Dispõe sobre loteamento e parcelamento do solo urbano e da outras providências.

LEI FEDERAL n 4771/65. Código florestal.

LIMA, A.M.L.P.; CAVALHEIRO, F. NUCCI, J.C.; SOUZA, M.A.L.B.; FIALHO, N.O.; DEL PICCHIA, P.C.D. Problemas de utilização na conceituação de termos como espaços livres, 
áreas verdes e correlatos. In: Congresso Brasileiro de Arborização Urbana, 5, São Luiz, 1994. Anais: São Luiz: Sociedade Brasileira de Arborização Urbana, 1994. p. 539-553.

LOMBARDO, M. A ilha de calor nas metrópoles. O exemplo de São Paulo. Hucitec, São Paulo, 244p. 1985.

NUCCl, J.C. Qualidade ambiental e adensamento: um estudo de planejamento da paisagem do distrito de Santa Cecília (MSP). Departamento de Geografia - FFLCH USP (tese de doutorato), 1996. 